\title{
Action of anticytoskeletal compounds on in vitro cytopathic effect, phagocytosis, and adhesiveness of Trichomonas vaginalis
}

\author{
C JULIANO, ${ }^{*}$ G MONACO $†$ P BANDIERA, $\ddagger$ G TEDDE $\ddagger$ P CAPPUCCINELli* \\ From the *Istituto di Microbiologia Medica, Università di Sassari, Sassari, $\uparrow$ Centro di Biologia, Università di \\ Lecce, Lecce, and $\ddagger$ Istituto di Anatomia Umana Normale, Università di Sassari, Sassari, Italy
}

SUMMARY The cytopathic effects of Trichomonas vaginalis treated with inhibitory concentrations of anticytoskeletal compounds (mebendazole, griseofulvin, colchicine, taxol, and cytochalasin B) were studied in mouse CL1D fibroblast cultures. The evaluation, at different times, of cell numbers and morphological alterations showed that cytopathic effect was considerably reduced when protozoa were pretreated with mebendazole and griseofulvin, whereas colchicine, taxol, and cytochalasin $B$ had less effect. Furthermore, treatment with mebendazole, griseofulvin, and colchicine decreased adhesiveness of the protozoan, whereas treatment with cytochalasin B and colchicine completely inhibited its phagocytic activity. From these results it may be concluded that alterations induced in the trichomonal cytoskeleton may affect its adhesiveness and its in vitro cytopathic effect, but there is no direct correlation between protozoan phagocytosis and its in vitro pathogenic effect.

Trichomonas vaginalis is one of the four trichomonal species (with Trichomonas gallinae, Tritrichomonas foetus, and Histomonas meleagridis) that have pathogenic strains (Honigberg BM, unpublished observation). It is the subject of careful investigations, not only because it is an aetiological agent of serious disease, especially in women, but also because there is a positive, although not necessarily causal, relation between urogenital trichomoniasis and cervical cancer. ${ }^{12}$

The first evidence of the pathogenicity of $T$ vaginalis was acquired by establishing experimental infections in different species of laboratory animals, which showed that different strains of $T$ vaginalis can differ in their inherent pathogenicity levels (for references see Honigberg ${ }^{3}$ ). The subcutaneous mouse assay compared the pathogenicity of different strains by simple evaluation of abscess volumes, ${ }^{4}$ and it produced results that agreed with those obtained from clinical considerations. ${ }^{45}$

A different approach to the study of the pathogenicity of $T$ vaginalis requires the use of cell cultures.

Address for reprints: Dr Claudia Juliano, Istituto di Tecnica Farmaceutica, Facoltà di Farmacia, Via Muroni 23, 07100 Sassari, Italy.

Accepted for publication 16 November 1986
This is not only a good alternative to the in vivo methods of evaluating the pathogenic potential (furthermore eliminating the variability of host dependent factors), but is also a suitable research tool to investigate the mechanisms by which flagellates can cause cellular damage. The use of cell cultures allowed the alterations produced in cells by $T$ vaginalis to be seen, ${ }^{6-9}$ and showed the biochemical alterations that followed protozoan infections. ${ }^{10}$ Furthermore, the damage induced by direct protozoan contact can be reproduced, at least in determinate experimental conditions, by exposing the cells to cell free filtrates of cultures of pathogenic strains of $T$ vaginalis, which indicates that toxins are produced. ${ }^{611}$

Despite these results, little is known about the intimate mechanisms of $T$ vaginalis pathogenicity. Current thinking suggests that protozoan pathogenicity may depend on variables such as adhesion, phagocytosis, or enzyme or toxin production, and that there may be different experimental approaches to this study.

As many cellular functions depend, more or less directly, on the cytoskeleton, and as this is well represented in $T$ vaginalis, especially with regard to the microtubular components, ${ }^{12}$ we attempted to see whether alterations induced in the trichomonal cyto- 
skeleton by specific inhibitors ${ }^{13}$ gave qualitative and quantitative modifications to its cytopathic in vitro effect, phagocytosis, and adhesion.

\section{Materials and methods}

\section{CHEMICALS}

Cytochalasin B (Aldrich Chemical Company), griseofluvin (Sigma), mebendazole (Janssen), and taxol (donated by Natural Products Branch, Division of Cancer Treatment, NCI, Bethesda, USA) were dissolved in dimethyl sulphoxide (DMSO) at final concentrations of $21 \mathrm{mmol} / 1$ cytochalasin B, $14 \mathrm{mmol} / 1$ griseofulvin, $34 \mathrm{mmol} / \mathrm{l}$ mebendazole, and $10 \mathrm{mmol} / \mathrm{l}$ taxol. Colchicine (Boehringer Mannheim) was dissolved in distilled water at a concentration of $25 \mathrm{mmol} / \mathrm{l}$. The DMSO concentrations used $(0 \cdot 1 \%)$ apparently do not affect protozoan viability.

\section{GROWTH CONDITIONS OF TRICHOMONAS VAGINALIS}

We used a virulent strain of $T$ vaginalis (TO-37), originally isolated from a patient with acute vaginal trichomoniasis. Protozoa were axenically cultured in agar free Diamond's medium supplemented with $10 \%$ heat inactivated calf serum, $500 \mathrm{mg} / 1$ streptomycin sulphate and $6 \mathrm{mg} / \mathrm{l}$ penicillin $\mathrm{G},{ }^{14}$ at $37^{\circ} \mathrm{C}$ in a $10 \%$ carbon dioxide atmosphere. Protozoa maintained in vitro for four weeks or longer showed a well known progressive attenuation of their pathogenicity for cell cultures ${ }^{5}$; this disadvantage could be eliminated by keeping the protozoa frozen at $-80^{\circ} \mathrm{C}$ in the presence of $10 \%$ DMSO and $30 \%$ calf serum and thawing them shortly before the experiments.

\section{CELL CULTURES}

CL1D mouse fibroblasts were cultured in monolayers at $37^{\circ} \mathrm{C}$ in a $10 \%$ carbon dioxide atmosphere, on $25 \mathrm{~cm}^{2}$ plastic bottles (Falcon) in RPMI 1640 medium (EUROBIO) supplemented with $10 \%$ heat inactivated fetal calf serum (Flow), $0.6 \mathrm{mg} / \mathrm{l}$ penicillin $\mathrm{G}$, and $100 \mathrm{mg} / 1$ streptomycin sulphate. For infection experiments, cells were seeded on glass coverslips ( $22 \mathrm{~mm}$ in diameter) into wells of 24 well polystyrene plates (Space Saver, Flow Laboratories) to reach the stage of semiconfluence after two days.

\section{INFECTION EXPERIMENTS}

Before carrying out the infection experiments, we needed to find the optimum number of $T$ vaginalis to inoculate into each well to obtain easily observable and evaluable effects; we therefore performed preliminary experiments by infecting the cells with different amounts of trichomonads. If $10^{4}$ or fewer trichomonads were added to each well the resulting cell damage was poor, and was evident only several hours after infection. In contrast, with the highest concentrations $\left(1 \times 10^{6} T\right.$ vaginalis per well $)$ the cells were entirely covered by the flagellates, which prevented observation of alterations of the culture with the light microscope; furthermore, the cytopathic effect was rapid and severe, with massive fibroblast detachment from the support in less than one hour. Under these conditions, it was obviously difficult to examine the cytopathic effect and to assess its kinetics. The most satisfactory results were achieved by infecting each semiconfluent fibroblast slide with $2 \times$ $10^{5}$ T vaginalis, and all subsequent experiments were performed at this concentration of protozoa.

In the inhibition experiments, we used flagellates that had been treated for 24 hours with antimicrotubular compounds (mebendazole $34 \mu \mathrm{mol} / \mathrm{l}$, colchicine $250 \mu \mathrm{mol} / \mathrm{l}$, griseofulvin $140 \mu \mathrm{mol} / \mathrm{l}$ ), with the microtubular stabilising agent, taxol, $10 \mu \mathrm{mol} / \mathrm{l}$, or with the microfilament inhibitor, cytochalasin B, $210 \mu \mathrm{mol} / \mathrm{l}$. Before each experiment, non-inhibited trichomonads from 24 hour cultures or treated for 24 hours with the inhibitors were counted in a Thoma haematocytometer, centrifuged at $700 \times g$ for 10 minutes, washed once with RPMI 1640 medium, and resuspended at a density of $2 \times 10^{5} / \mathrm{ml}$ in RPMI 1640 and $10 \%$ fetal calf serum containing $50 \mu \mathrm{mol} / 1$ $\beta$-mercaptoethanol. Although Diamond's medium is the optimum medium for growing $T$ vaginalis, these protozoa proliferate in cell culture media, such as RPMI 1640, although at slower rates (unpublished observation). To each well containing cells, $1 \mathrm{ml}$ of trichomonad suspension was added; to the wells with control cells, $1 \mathrm{ml}$ of RPMI 1640 medium containing $10 \%$ fetal calf serum and $50 \mu \mathrm{mol} / 1$ $\beta$-mercaptoethanol was added. The plates were then incubated at $37^{\circ} \mathrm{C}$ in a $10 \%$ carbon dioxide atmosphere. After 2, 3, or 6 hours the medium was removed from the wells. The slides were gently washed with $0.14 \mathrm{~mol} / 1$ phosphate buffered saline (PBS), fixed with methanol at room temperature for 10 minutes, stained for 45 minutes with Giemsa's solution (Merck) diluted at a ratio of $1: 10$ with $0.065 \mathrm{~mol} / \mathrm{l}$ sodium phosphate buffer (sodium biphosphate $9 \cdot 2 \mathrm{~g}$ and sodium phosphate $23.9 \mathrm{~g}, \mathrm{pH} 6.8$ ), washed twice with distilled water, air dried, and mounted with Permount. In such prepared slides, the cell number per field was counted in 10 microscope fields using the automatic image analyser Zeiss IBAS 2, applying version $5 \cdot 21$ of program KONTRON 64 .

\section{PHAGOCYTOSIS EXPERIMENTS}

For the phagocytosis tests we used a strain of $E s-$ cherichia coli isolated from pathology material, maintained on nutrient agar slants (Difco) at room temperature, and transferred at three to four month intervals. Before each experiment, a bacterial loop 
was suspended in $10 \mathrm{ml}$ of nutient broth (Difco) and incubated overnight at $37^{\circ} \mathrm{C}$. By seeding $10 \mu \mathrm{l}$ of such suspension in $10 \mathrm{ml}$ of medium and incubating at $37^{\circ} \mathrm{C}$ for four to five hours we obtained a culture whose absorbance, read with a Pye Unicam SP6-4000 UV spectrophotometer at $500 \mathrm{~nm}$, was $0 \cdot 2$, which roughly corresponded to 1 to $2 \times 10^{6}$ bacteria $/ \mathrm{ml}$.

Tvaginalis, both normal from a 24 hour culture and inhibited for 24 hours with different concentrations of mebendazole, colchicine, taxol, or cytochalasin B, were counted, centrifuged at $700 \times g$ for 10 minutes, and resuspended in Diamond's medium supplemented with $10 \%$ calf serum at a cell density of $1-2 \times 10^{6} / \mathrm{ml}$. Bacteria suspended in $1 \mathrm{ml}$ of nutrient broth were added to $1 \mathrm{ml}$ of trichomonads, giving a final ratio of $1: 1$, and the mixture was incubated at $37^{\circ} \mathrm{C}$ under continuous rotation (at four revolutions a minute). After one hour, the samples were centrifuged at $110 \times g$ for four minutes to remove trichomonads (in these conditions the non-ingested bacteria remain in suspension in the supernate), and tenfold dilutions in saline of the supernates were plated in duplicate on nutrient agar and incubated overnight at $37^{\circ} \mathrm{C}$. To evaluate the number of viable remaining bacteria, only plates containing between 30 and 300 colonies were counted.

SCANNING ELECTRON MICROSCOPY (SEM)

For scanning electron microscopy, infected cultures were fixed 30 minutes, one hour, and four hours after infection. The medium was removed, and the slides were rinsed twice for five to 20 minutes with $0 \cdot 1 \mathrm{~mol} / 1$ sodium cacodylate buffer, $\mathrm{pH} 7 \cdot 2$; cells were then fixed with $2.5 \%$ glutaraldehyde (EM grade) in $0.1 \mathrm{~mol} / \mathrm{l}$ sodium cacodylate buffer at room temperature for one hour. After being washed three times for 20 minutes each with sodium cacodylate buffer, cells were postfixed in $1 \%$ osmium tetroxide in the same buffer at room temperature for one hour, washed three times in cacodylate buffer, and finally washed in distilled water. Cells were then dehydrated in 2.2 dimetoxipropane-hydrochloric acid ${ }^{15}$ followed by $100 \%$ acetone, and critical point dried by a Polaron apparatus with carbon dioxide as transitional fluid. The coverslips were covered with gold in Edwards S-150 sputter coater and observed with ISI DS130 and JEOL JSM35 electron microscopes at 25 and $30 \mathrm{kv}$.

EVALUATING ADHESIVENESS OF TVAGINALIS, BOTH NORMAL AND TREATED WITH

CYTOSKELETON INHIBITORS

In each slide at least 1000 cells were examined under the light microscope at $1250 \times$ magnification, and the number of trichomonads adherent to each cell was counted. The adhesiveness of $T$ vaginalis was expressed as a ratio of $T$ vaginalis to cells.

\section{Results}

BEHAVIOUR OF NON-INHIBITED TVAGINALIS IN CELL CULTURES: OBSERVATION BY LIGHT AND SCANNING ELECTRON MICROSCOPY

On examining infected cultures under the inverted microscope 10 to 15 minutes after inoculation, the flagellates had settled on the cells and had swum in all directions over them. After about 30 minutes, flagellates no longer showed wide movements and adhered firmly to the fibroblasts, even when the plate was shaken. The scanning electron microscope images showed that $T$ vaginalis adhered to the cell surface and to slides by pseudopodia, especially by thin filopodial tips. Even within the first hour, under the light microscope, morphological changes of the cultures of fibroblasts began to appear. Examining the cells separately, we observed that some were no longer spread out, but were stretched and spindle shaped; many cell elements had indented contours and showed cytoplasmic retraction and cell body roundness (fig 1). It was interesting to note that morphologically normal fibroblasts often lay next to cells showing these pathological changes (fig 1). This indicated that the nature of the cytopathic effect was strictly local and that contact between protozoa and cells was important. At the longest incubation times (up to six hours), the events described increased until they affected almost all the cells; a large number of cells came off slide surfaces, giving rise to the formation of acellular irregularly shaped areas (fig 1).

Observations using the scanning microscope substantially confirmed these findings. A remarkable decrease in or even loss of microvilli was noted, especially at protracted incubation times, whereas microvilli were evident on the surface of the control cells (fig 2).

BEHAVIOUR OF INHIBITED TVAGINALIS IN CELL CULTURES: OBSERVATION BY LIGHT AND SCANNING ELECTRON MICROSCOPY

Simple observation of the infected cultures, both by light and by scanning electron microscopy, showed that the cytopathic effect of $T$ vaginalis decreased as a result of pretreatment of the flagellates with some cytoskeletal inhibitors. The fibroblasts, especially when infected with $T$ vaginalis treated with mebendazole or griseofulvin, did not display signs of damage during the first hour of infection; the cell free areas, which were present in non-infected fibroblasts, were not observed. This protective effect of all cytoskeletal inhibitors tested, except cytochalasin B, decreased progressively so that values at about the sixth hour in 


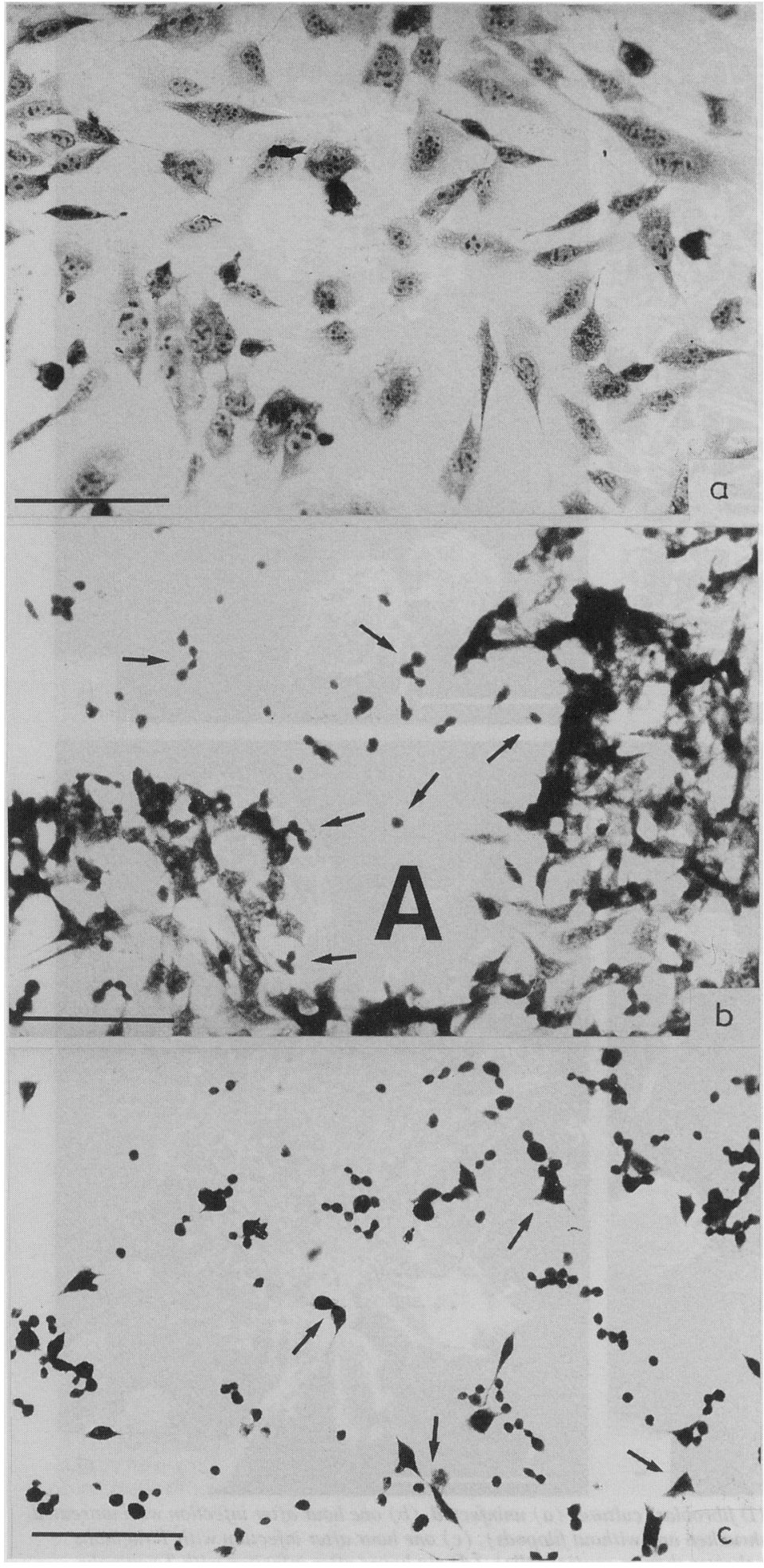

Fig 1 Light microscopy of semiconfluent mouse CL1D fibroblast cultures (a) uninfected, (b) two hours after inoculation with $T$ vaginalis (large acellular area $(A)$ containing parasites (arrows), cells lining the lesion are rounded and retracted, whereas unparasitised areas seem to be normal). (c) six hours after inoculation with $T$ vaginalis (very few cells (arrows), rounded or spindle shaped, adhere to coverslip). Giemsa, scale bars $=$ $100 \mu \mathrm{m}$.) 

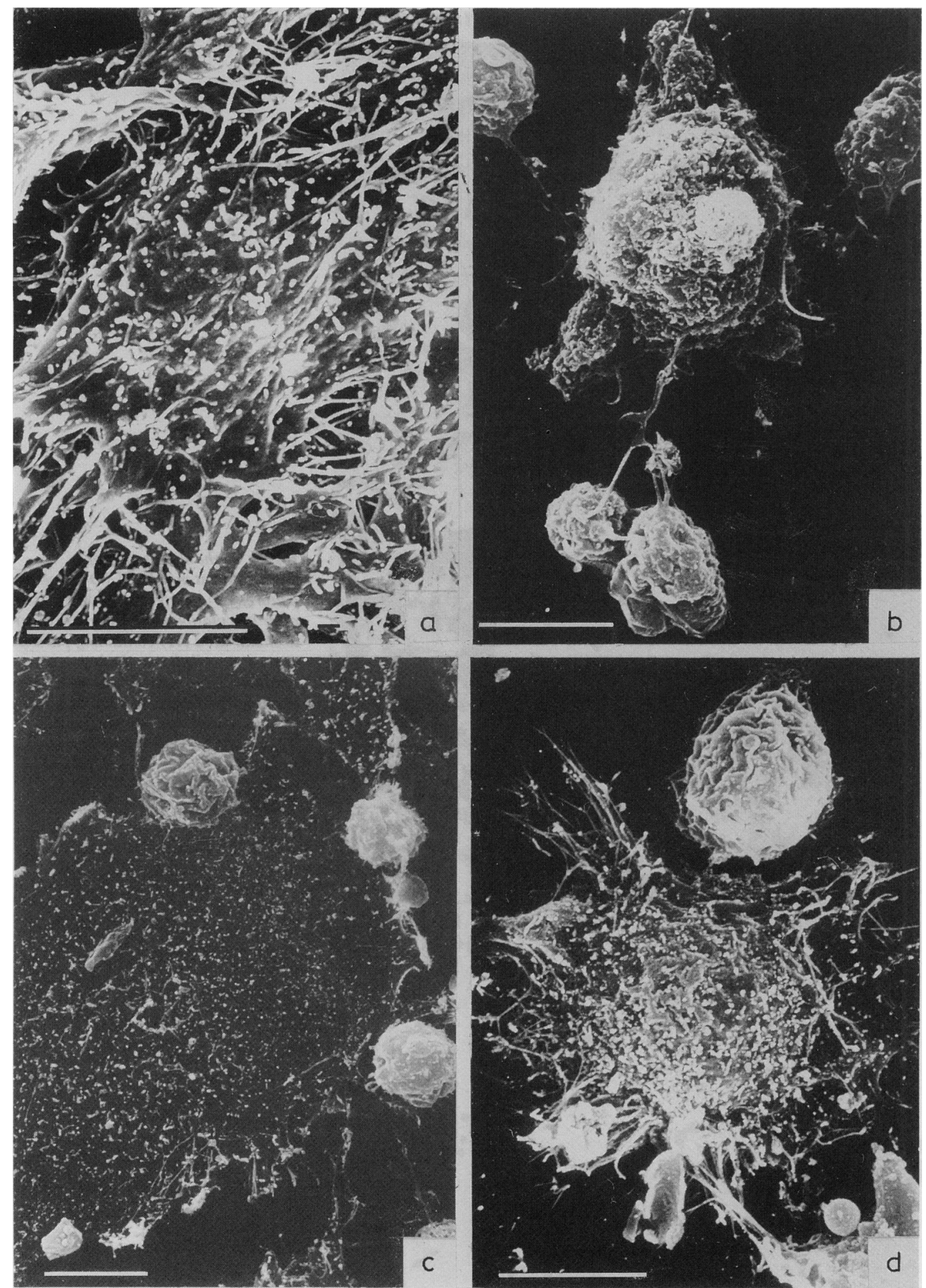

Fig 2 Scanning electron microscopy of CL1D fibroblast cultures (a) uninfected, (b) one hour after infection with untreated $T$ vaginalis (dramatic cytopathic effect; cell shrunken and without filopods), (c) one hour after infection with $T$ vaginalis treated with mebendazole $34 \mu \mathrm{mol} / \mathrm{l}$ (filopods shorter than in control cells), (d) six hours after infection with $T$ vaginalis treated with mebendazole (cell dramatically shrunken like cells infected by untreated trichomonads, but some filopods are still present $)$. (Scale bars $=10 \mu \mathrm{m}$.) 
fibroblasts infected with trichomonads treated with mebendazole were similar to those observed with untreated protozoa (fig 2(d)).

The pathogenicity of $T$ vaginalis in fibroblast cultures, evaluated by a clearly measurable variable such as mean cell number per field, enabled us to measure exactly the degree of reduction in cytopathic effect that occurred when $T$ vaginalis was pretreated with cytoskeletal inhibitors. Figure 3 shows that, after incubation for two hours, the mean cell number per field after infection with non-inhibited $T$ vaginalis was far smaller than in non-infected fibroblasts, and it decreased regularly after incubation for three and six hours. In contrast, experimental cell numbers were high during the first hours after pretreatment of $T$ vaginalis with mebendazole, but decreased subsequently to reach, at about the sixth hour, values similar to those obtained with untreated $T$ vaginalis. Intermediate values were obtained with griseofulvin, colchicine, and taxol.

\section{RESULTS OF THE PHAGOCYTOSIS EXPERIMENTS}

Figure 4 shows that colchicine and cytochalasin $B$ entirely inhibited the phagocytic activity of $T$ vaginalis towards $E$ coli, whereas pretreatment with taxol or mebendazole reduced it to $52 \%$ or $54 \%$ respectively of that of untreated trichomonads.

RESULTS OF ADHESIVENESS EVALUATION

The maximum adhesiveness to fibroblasts was dis- played by non-inhibited $T$ vaginalis, especially soon after infection. The ratios of $T$ vaginalis to cells were always lower when protozoa were inhibited with anticytoskeletal substances, particularly mebendazole, griseofulvin, and colchicine (table).

\section{Discussion}

The treatment of $T$ vaginalis with some anticytoskeletal inhibitors can reduce, in our experimental conditions and particularly soon after infection, the protozoan cytopathic effect in vitro. This was more evident for mebendazole, griseofulvin, and, less noticeably, colchicine, all of which induce alterations in the trichomonal microtubular system (unpublished observation). The cytopathic effect on fibroblasts was measured by modification of the cellular shape (cytoplasmic retraction and cell body rounding) and by reduction of the mean cell number per microscope field. The evaluation of these variables in cell cultures infected by $T$ vaginalis treated with inhibitors, and their comparison with the results for controls, allowed us to estimate exactly the inhibition of the cytopathic effect. Caution must be used in interpreting results of experiments with inhibitors, as the inhibition of cytopathic effect with anticytoskeletal compounds could be due to action on other cell targets. Nevertheless, a direct correlation seems to be likely because the substances more active in blocking the in vitro cytopathic effect (mebendazole and gri-

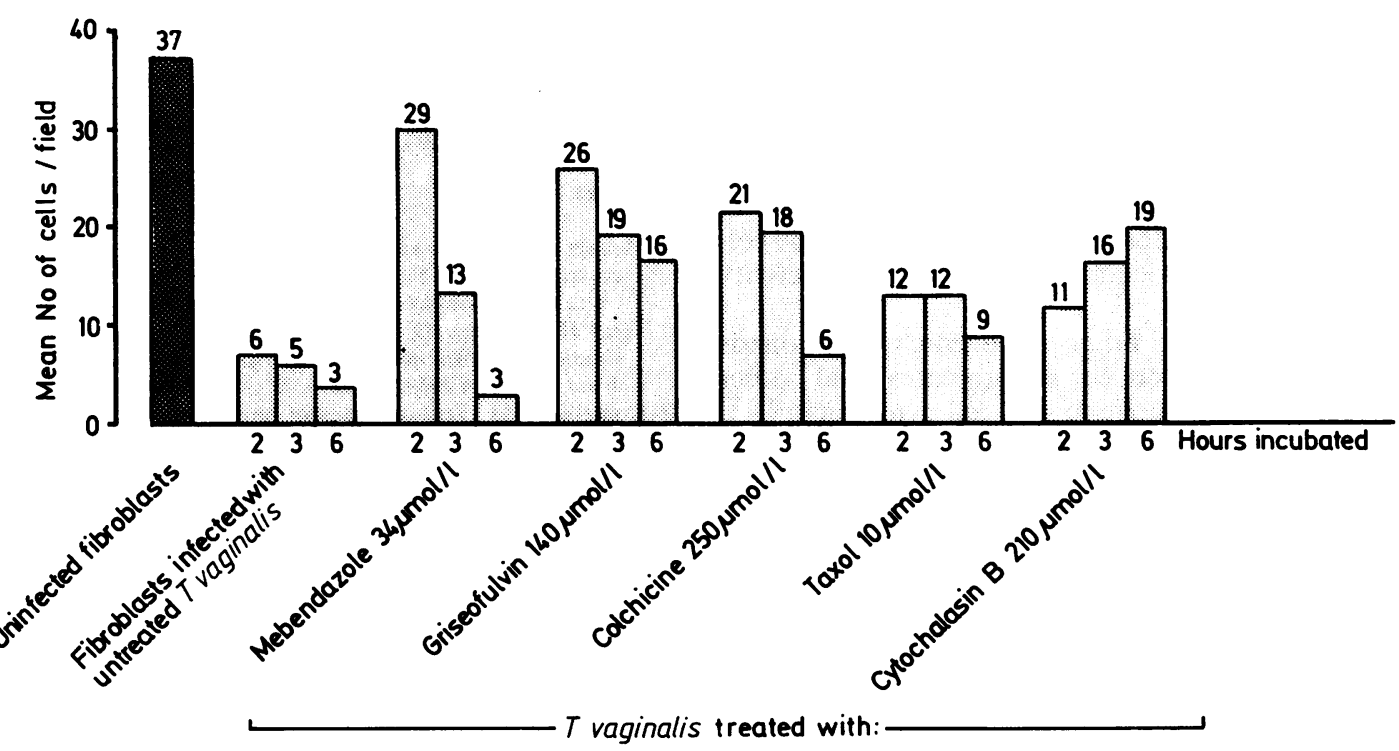

Fig 3 Mean numbers of cells/microscopic field (in slides observed at $200 \times$ magnification) in CL1D fibroblast cultures incubated for 2, 3, and 6 hours with live pathogenic T vaginalis untreated or treated with anticytoskeletal compounds. 


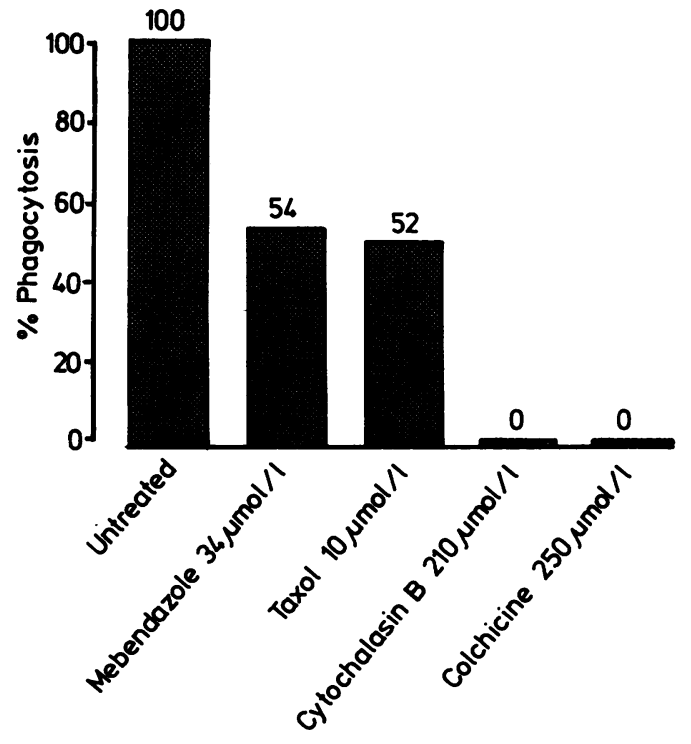

$T$ vaginalis treated with:

Fig 4 Phagocytic activity (\%) of T vaginalis untreated or after treatment for 24 hours with anticytoskeletal compounds.

seofulvin) are also those more effective phenomena dependent on cytoskeletons, ${ }^{14}$ and give pronounced alterations of trichomonal microtubular structures (unpublished observation). In addition, none of the tested compounds shows metabolic effects, such as inhibition of synthesis of protein, deoxyribonucleic acid (DNA), or ribonucleic acid (unpublished results).

By investigating how inhibitors affect phagocytosis, we observed that the phagocytic activity of $T$ vaginalis does not appear to be correlated with its cytopathic effect, as compounds more effective in inhibiting phagocytosis (cytochalasin B and colchicine) reduce trichomonal cytopathic activity poorly.

As $T$ vaginalis and other pathogenic trichomonads are known to produce exoproteases and other enzymes possibly implicated in cell cytotoxicity ${ }^{16} 17$ during growth and multiplication, future development in this work should clarify how inhibitors can affect the ability of $T$ vaginalis to secrete enzymes or toxic substances.

Many strains of $T$ vaginalis are known to adhere to several substrates, including cultured cells, ${ }^{7}$ glass, ${ }^{18}$ and plastic (Cappuccinelli P, et al, unpublished observation). Our experiments indicate that flagellates treated with (especially) colchicine, mebendazole, and griseofulvin exhibit a lower ability than controls to adhere to fibroblasts. As normal fibroblasts are often adjacent to damaged cells, which may indicate a "short range" action of T vaginalis on fibroblasts, the adhesiveness may play an important part in pathogenicity, as for other protozoa, ${ }^{1920}$ both by making possible a direct mechanical action and by allowing eventual protozoan toxins to act more rapidly and at higher concentrations. This could explain why supernatants of $T$ vaginalis cultures give the same, although reduced, effects as the cultures. ${ }^{11}$

Another fact arising from this work is that the reduction in the cytopathic effect of $T$ vaginalis resulting from treatment with cytoskeletal inhibitors is maximum soon after contact between $T$ vaginalis and cells, and decreases considerably at longer incubation times. As the anticytoskeletal action of the tested inhibitors is not reversible, ${ }^{13}$ the pathogenicity of $T$ vaginalis, like that of other protozoa, ${ }^{21}{ }^{22}$ (and Honigberg BM, unpublished observations) could have various components, some of which might depend on the cytoskeleton, and others, which emerge more slowly, characterised by a different mechanism of action.

This study was supported by grants from the Italian Ministero della Pubblica Istruzione and Consiglio Nazionale delle Ricerche (No 83.00634.52).

References

1 Meisels A. Dysplasia and carcinoma of the uterine cervix. IV. A correlated cytologic and hystologic study with special emphasis on vaginal microbiology. Acta Cytol 1969;13:224-31.

2 Teras JK, Kaarma H. Characteristics of the colpo-cytological changes in women infested with Trichomonas vaginalis Donné. Wiad Parazytol 1969;15:327-9.

3 Honigberg BM. Trichomonads of importance in human medi-

Table Adhesiveness of Trichomonas vaginalis untreated or pretreated for 24 hours with anticytoskeletal compounds, to CL1D fibroblasts (adhesiveness expressed as ratio of $T$ vaginalis to fibroblasts)

\begin{tabular}{|c|c|c|c|}
\hline \multirow{2}{*}{$\begin{array}{l}T \text { vaginalis } \\
\text { treated with }\end{array}$} & \multicolumn{3}{|c|}{ After incubation for: } \\
\hline & 2 hours & 3 hours & 6 hours \\
\hline $\begin{array}{l}\text { Untreated } \\
\text { Mebendazole } 34 \mu \mathrm{mol} / 1 \\
\text { Colchicine } 250 \mu \mathrm{mol} / 1 \\
\text { Griseofulvin } 140 \mu \mathrm{mol} / 1 \\
\text { Taxol } 10 \mu \mathrm{mol} / 1 \\
\text { Cytochalasin B } 210 \mu \mathrm{mol} / 1\end{array}$ & $\begin{array}{l}0 \cdot 60 \\
0 \cdot 24 \\
0 \cdot 16 \\
0 \cdot 30 \\
0 \cdot 32 \\
0 \cdot 35\end{array}$ & $\begin{array}{l}0.45 \\
0.34 \\
0.28 \\
0.26 \\
0.40 \\
0.41\end{array}$ & $\begin{array}{l}0.54 \\
0.48 \\
0.25 \\
0.35 \\
0.32 \\
0.40\end{array}$ \\
\hline
\end{tabular}


cine. In: Kreier JP, ed. Parasitic protozoa. Vol II. New York: Academic Press, 1978:275-454.

4 Honigberg BM. Comparative pathogenicity of Trichomonas vaginalis and Trichomonas gallinae to mice. I. Gross pathology, quantitative evaluation of virulence, and some factors affecting pathogenicity. J Parasitol 1961;47:545-71.

5 Kulda J, Honigberg BM, Frost JK, Hollander DH. Pathogenicity of Trichomonas vaginalis. Am J Obstet Gynecol 1970; 108:908-18.

6 Farris VK, Honigberg BM. Behaviour and pathogenicity of Trichomonas vaginalis Donné in chick liver cell cultures. $J$ Parasitol 1970;56:849-82.

7 Heath JP. Behaviour and pathogenicity of Trichomonas vaginalis in epithelial cell cultures: a study by light and scanning electron microscopy. British Journal of Venereal Diseases 1981; 57:106-17.

8 Brasseur P, Savel J. Evaluation de la virulence des souches de Trichomonas vaginalis par l'étude de l'effect cytopathogène sur culture de cellules. C R Soc Biol (Paris) 1982;176:849-60.

9 Alderete JF, Pearlman E. Pathogenic Trichomonas vaginalis cytotoxicity to cell culture monolayers. British Journal of Venereal Diseases 1984;60:99-105.

10 Sharma NN, Honigberg BM. Cytochemical observations on malic dehydrogenase, lipase, non specific esterase, and monoamino oxidase in chick liver cell cultures infected with Trichomonas vaginalis. J Protozool 1969;16:171-81.

11 Hogue MJ. The effect of Trichomonas vaginalis on tissue-culture cells. American Journal of Hygiene 1943;37:142-52.

12 Nielsen MH, Ludvik J, Nielsen R. On the ultrastructure of Trichomonas vaginalis Donné. Journal de Microscopie (Paris)
1966;5:229-50.

13 Juliano C, Martinotti MG, Cappuccinelli P. "In vitro" effect of microtubule inhibitors on Trichomonas vaginalis. Microbiologica 1985;8:31-42.

14 Diamond LS. The establishment of various trichomonads of animals and man in axenic cultures. $J$ Parasitol 1957;43:488-90.

15 Müller LL, Jacks TJ. Rapid chemical dehydration of samples for electron microscopic examination. J Histochem Cytochem 1975;23:107-10.

16 McLaughlin J, Müller M. Purification and characterization of a low molecular weight thiol proteinase from the flagellate protozoan Tritrichomonas foetus. J Biol Chem 1979;254:1526-33.

17 Honigberg BM. Biological and physiological factors affecting pathogenicity of trichomonads. In: Biochemistry and physiology of protozoa. Vol 2. New York: Academic Press, 1979:409-27.

18 Lumsden WHR, Robertson DHH, McNeillage GJC. Isolation, cultivation, low temperature preservation and infectivity titration of Trichomonas vaginalis. British Journal of Venereal Diseases 1966;42:145-54.

19 Kobiler D, Mirelman D. Lectin activity in Entamoeba histolytica trophozoites. Infect Immun 1980;29:221-5.

20 Seed TM, Kreier JP. Surface properties of extracellular malaria parasites: electrophoretic and lectin-binding characteristics. Infect Immun 1976;14:1339-47.

21 Guerrant RL, Brush J, Radvin JI, Sullivan JA, Mandell GL. Interaction between Entamoeba histolytica and human polymorphonuclear neutrophils. J Infect Dis 1981;143:83-93.

22 Gitler C, Calef E, Rosemberg I. Cytopathogenicity of Entamoeba histolytica. Philos Trans R Soc Lond [Biol] 1984;307:73-85. 